\title{
PERAN MOTIVASI DAN KINERJA PENYULUH PERTANIAN DALAM MENGUBAH PERILAKU PETANI JAGUNG
}

\section{The Role Of Motivation And Performance Ofagricultural Extensionist In Changing Behavior Of Corn Farmers}

\author{
Mohamad Ikbal Bahua \\ Program Studi Agroteknologi Fakultas Pertanian Universitas Negeri Gorontalo \\ Email: mohamad.bahua@ung.ac.id
}

\begin{abstract}
The purpose of this study are: (1) to identify the influence of competence that can improve the performance of agricultural extension in the development of maize farming, (2) to examine the importance of competence and performance of agricultural extension on the behavior of corn farmers, and (3) to analyze the impact of extension performance agriculture corn farmers on changing behaviors. Research conducted in Gorontalo Province fromMarch until June 2018. The study usesex-post facto. The smallest unit of observation is the agricultural extensionist with totalnumber of 118 persons. The data collected through interviews by using a questionnaire and analyzed by using LISREL 8.30 SEM program. Results of the study showed that the influence of competence on the performance of agricultural extension influenced by the capacity building and needs affiliated. The variable motivation of extension agents indirect influence on corn farmers' behavior changes, while the performance of agricultural extension through the dimensions of quality of appreciation of cultural diversity and quality of management information have direct impact on farmer behavior with the coefficient of 0.83. Impact of agricultural extension agent performance impact on changing behaviors through a dimension of competence corn farmers and farmer participation have coefficient of determination $\left(R^{2}\right)$ equal to 69 percent.
\end{abstract}

Keyword: Motivation, performance, extension agriculture, behavior farmer

Abstrak
Tujuan penelitian ini adalah untuk (1) mengidentifikasi pengaruh motivasi yang
dapat meningkatkan kinerja ketua penyuluhan pertanian dalam pengembangan
jagung, (2) menilai pengaruh motivasi dan kinerja penyuluhan pertanian
terhadap perubahan perilaku petani jagung, dan (3) menganalisis dampak
kinerja penyuluh pertanian dalam mengubah perilaku petani jagung. Penelitian
dilaksanakan di Provinsi Gorontalo dari bulan Maret sampai dengan Juni 2018 .
Metode penelitian adalah "ex post facto," Unit analisis penelitian ini adalah
penyuluh pertanian yang berjumlah 118 orang. Data diperoleh dengan
wawancara menggunakan kuesioner. Data dianalisis menggunakan LISREL 8.30
program SEM (Strcture Equation Models). Hasil penelitian menunjukkan bahwa
pengaruh motivasi pada kinerja penyuluh pertanian dipengaruhi oleh dimensi
kemampuan pengembangan potensi diri dan kebutuhan berafiliasi. Peubah
motivasi penyuluh berpengaruh tidak langsung pada perubahan perilaku petani
jagung, sedangkan kinerja penyuluh pertanian melalui dimensi kualitas
mengapresiasi keragaman budaya dan kualitas pengelolaan informasi
berpengaruh langsung pada perilaku petani dengan koefisien pengaruh sebesar
0.83 satuan.Dampak pengaruh kinerja penyuluh pertanian pada perubahan
perilaku petani jagung melalui dimensi kompetensi petani dan partisipasi petani
dengan keofisien determinasi ( $\mathrm{R}^{2}$ ) sebesar 69 persen.


Kata kunci: motivasi, kinerja, penyuluh pertanian, perilaku petani.

Sitasi: Bahua M. I., 2018. Peran Motivasi Dan Kinerja Penyuluh Pertanian Dalam Mengubah Perilaku Petani Jagung, JSEP 14(3): 225 - 232.

\section{Pendahuluan}

Motivasi merupakan upaya penguatan kepercayaan diri individu dalam melakukan aktivitas hidupnya sesuai dengan kemampuan dan pengetahuannya. Motivasi berhubungan erat dengan perencanaan organisasi terutama pada tahapan implementasi dan evaluasi. Suatu organisasi akan terbantu dengan motivasi individu yang dapat melaksanakan tugas sesuai dengan potensi, prestasi dan keahliannya. Motivasi individu dalam organisasi dapat berasal dari dalam diri individu maupun dari luar diri individu. Menurut Dahama dan Bhatnagar (1980), motivasi merupakan kombinasi dari kepentingan, keinginan, kebutuhan dan perasaan individu dalam mencapai suatu tujuan yang disadari keberadaannya untuk meningkatkan kesejahteraan dan keberlangsungan kehidupan. Koontz et al.,(1980) menjelaskan bahwa motivasi adalah suatu pernyataan lahiriah dari individu yang dilakukan berdasarkan daya kekuatan untuk bertindak atau bergerak secara langsung melalui saluran perilaku yang mengarah pada tujuan atau sasaran.

Maslow (1956) mengembangkan teori motivasi melalui hirarki kebutuhan masing-masing individu. Motivasi melalui hirarki kebutuhan Maslow di bagi menjadi dua bagian utama, yaitu: (1) kebutuhan dasar yang terdapat pada hirarki paling bawah yang terdiri dari: (a) kebutuhan fisiologis, (b) kebutuhan akan rasa aman, (c) kebutuhan akan cinta dan harta (sosial), (2) kebutuhan tumbuh yang berada di atas kebutuhan dasar yang terdiri dari: (a) kebutuhan akan penghargaan (status) dan (b) kebutuhan akan aktualisasi diri.McClelland (1961) mengembangkan teorimotivasi berprestasi (achievement motivation) yang berhubungan dengan tiga kebutuhan, yaitu: (1)kebutuhan akan prestasi (need of achievement) n-Ach, (2) kebutuhan akan kekuasaan (need of power) n-Power dan (3) kebutuhan berafiliasi (need of affiliation) n-Affil.Herzberg (2000) menjelaskan bahwa, motivasi terdiri dari dua faktor yang memengaruhi kondisi pekerjaan seseorang, yaitu; (1) faktor pemuas "motivation factor" yang disebut juga satisfier atau intrinsic motivation, yaitu faktorfaktor yang sifatnya intrinsik atau bersumber dalam diri seseorang dan (2) faktor pemelihara"hygienes" yang disebut juga disatisfier atau exstrinsic motivation, yaitu faktor-faktor sifatnya yang bersumber dari luar diri dan turut menentukan perilaku seseorang dalam kehidupannya.

Motivasi dapat diartikan sebagai kekuatan (energi) seseorang yang dapat menimbulkan tingkat persistensi dan entusiasmenya dalam melaksanakan suatu kegiatan, baik yang bersumber dari dalam diri individu (motivasi intrinsik) maupun dari luar individu (motivasi ekstrinsik). Seberapa kuat motivasi yang dimiliki individu akan banyak menentukan kualitas perilaku yang ditampilkannya, baik 
dalam konteks belajar, bekerja maupun dalam kehidupannya. Kajian tentang motivasi memiliki daya tarik tersendiri bagi kalangan pendidik, manajer dan peneliti, terutama dikaitkan dengan kepentingan pencapaian kinerja seseorang.

Pada dasarnya motivasi dapat mendorong penyuluh pertanian untuk bekerja keras, sehingga dapat mencapai tujuan mereka. Hal ini akan meningkatkan produkitvitas kerja penyuluh yang berdampak pada pencapaian tujuan lembaga penyuluhan. Sumber motivasi tersebut antara lain: (1) kemungkinan berkembang, (2) jenis pekerjaan dan (3) perasaan bangga diterima petani setempat. Di samping itu terdapat beberapa aspek yang berpengaruh pada motivasi kerja penyuluh, yakni: kebutuhan untuk berprestasi, kebutuhan untuk berafiliasi, kebutuhan untuk kekuasaan, rasa aman dalam bekerja, mendapatkan gaji yang adil dan kompetitif, lingkungan kerja yang menyenangkan, penghargaan atas prestasi kerja dan perlakuan yang adil dari organisasi penyuluh.

Kinerja (performance)merupakanoutput dari prestasi kerja individu yang didasarkan pada beban kerja individu dalam suatu organisasi formal maupun non formal. Yuchtman dan Seashore (1967) menjelaskan kinerja ialahhasil pengukuran kemampuan dari organisasi yang mencakup persepsi keberhasilan individu dalam mengakses potensi sumberdaya yang terbatas untuk keberlanjutan program dan tujuan organisasi. Menurut Gruneberg (1979) kinerja ialah perilaku yang ditunjukkan secara nyata oleh individu sebagai wujud keberhasilan pada pekerjaan yang diukur berdasarkan hasil kerja, kuantitas dan kualitas kerja serta beban kerja.Bernardin dan Russel (1993) menjelaskanbahwa, kinerja merupakan catatan hasil kerja individu dari beban serta tugas kerja yang diberikan kepadanya yang diukur berdasarkan periode waktu tertentu.

Kinerja penyuluh yang baik perlu untuk meyakinkan pembuat kebijakan dan anggaran pembangunan agar tetap mengalokasikan cukup dana untuk membiayai penyuluhan dalam menunjang pembangunan daerah. Penyuluh pertanian harus berusaha mengembangkan program penyuluhan yang sesuai dengan potensi daerah dan permintaan pasar untuk memenuhi berbagai macam kebutuhan masyarakat. Kinerja penyuluh pertanian yang baik berdampak pada perbaikan kinerja petani dalam meningkatkan produksi usahatani. Kinerja penyuluh ini terarah pada pemecahan masalah yang dihadapi oleh petani dalam melaksanakan usahatani.

Evaluasi kinerja penyuluh pertanian dapat menunjukkan motivasi penyuluh dalam memberikan informasi yang dibutuhkan oleh petani, baik teknologi budidaya, harga, akses pasar dan permodalan maupun kebijakan pembangunan pertanian di wilayah kerja penyuluh. Dalam hubungan ini penyuluh harus memiliki kemampuan menyusun rencana pembelajaran yang akan diimplementasikan melalui metode dan media pembelajaran yang efektif dan efisien sesuai dengan jumlah kebutuhan masyarakat.

Informasi tentang kinerja penyuluh perlu juga untuk memertahankan motivasi kerja penyuluh. Penyuluh yang fokus pada prestasi kerja mereka akan berusaha 
untuk tidak sekedar mempertahankan prestasi tersebut, akan tetapi untuk lebih meningkatkan capaian-capaian yang telah diraih. Informasi yang diperoleh dari evaluasi kinerja penyuluh itu dapat juga menunjukkan kelemahan yang masih ada dalam diri penyuluh pada berbagai aspek. Dalam hubungan ini supervisor dapat memotivasi penyuluh untuk memperbaiki diri mereka, apakah dengan mengikuti pelatihan-pelatihan yang spesifik penyuluhan, pelatihan teknik pertanian, studi mandiri atau melanjutkan pendidikan formal kejenjang yang lebih tinggi.

\section{Metode Penelitian}

Penelitian dilaksanakan di Provinsi Gorontalo yang meliputi 5 (lima) daerah kabupaten dan satu kota. Pertimbangan lokasi penelitian, karena umumnya petani di Provinsi Gorontalo membudidayakan jagung sebagai tanaman pangan utama untuk memenuhi ekonomi dan pendapatan keluarga. Metode penelitian yang digunakan adalah ex post facto, yaitu penelitianyang menjelaskan peristiwa yang telah terjadi melalui keterkaitan antar peubah penelitian berdasarkan model persamaan struktural faktor-faktor yang mempengaruhi motivasi dan kinerja penyuluh pertanian. Obyek penelitian ini adalah penyuluh pertanian. Sampel penyuluh sebanyak 118 orang yang diambil secara random sampling proporsional dari 481 populasi penyuluh di Provinsi Gorontalo. Dengan menggunakan rumus Slovin sebaran sampelpenyuluh pertanian untuk masing-masing wilayah penelitian adalah:Kabupaten Gorontalo 43 penyuluh, Kabupaten Bone Bolango 22 penyuluh, Kabupaten Boelemo 20 penyuluh, Kabupaten Pohuwato 20 penyuluh, Kabupaten Gorontalo Utara 7 penyuluh dan Kota Gorontalo 6 penyuluh. Sumber data pada penelitian ini ialah data primer dan data sekunder. Data primer diperoleh melalui wawancara langsung dengan responden melalui panduan kuesioner. Pertanyaan pada kuesioner terdiri dari variabel motivasi penyuluh, yaitu; dimensi: (1) pengembangan potensi diri, (2) pengakuan petani, (3) penghasilan, (4) kebutuhan untuk berprestasi, (5) kebutuhan untuk berafiliasi, dan (6) kebutuhan untuk kekuasaan. Kinerja penyuluh pertanian, terdiri dari dimensi: (1) melakukan aksi sosial, (2) mengapresiasi keragaman budaya, (3) merencanakan program penyuluhan, (4) memanfaatkan sumberdaya lokal, (5) mengelola informasi penyuluhan, (6) membangun hubungan interpersonal, (7) menyelenggarakan penyuluhan, (8) menerapkan kepemimpinan, (9) manajemen organisasi, (10) mengembangkan profesionalisme penyuluh dan (11) menerapkan bidang keahlian teknis. Sedangkan data sekunder diperoleh melalui berbagai dokumen resmi dari dinas instansi yang berhubungan dengan penyuluhan pertanian. Analisis data pada penelitian ini menggunakan SEM (Structural Equation Model).

\section{Hasil dan Pembahasan}

\subsection{Motivasi dan Kinerja Penyuluh Pertanian}

Motivasi dan kinerja penyuluh pertanian berdasarkan model struktural berpengaruh pada perubahan perilaku petani sesuai penjelasan Gambar 1 yang menunjukkan jalur pengaruh antar peubah yang dapat dirumuskan persamaan model strukturalnya sebagai berikut:

$$
\mathrm{Y} 1=0,22 \mathrm{X} \text { dan } \mathrm{Y} 2=0,83 \mathrm{Y} 1
$$


Keterangan:

$\mathrm{X}=$ Motivasi penyuluh, $\mathrm{Y} 1=$ kinerja penyuluh, $\mathrm{Y} 2=$ perilaku petani

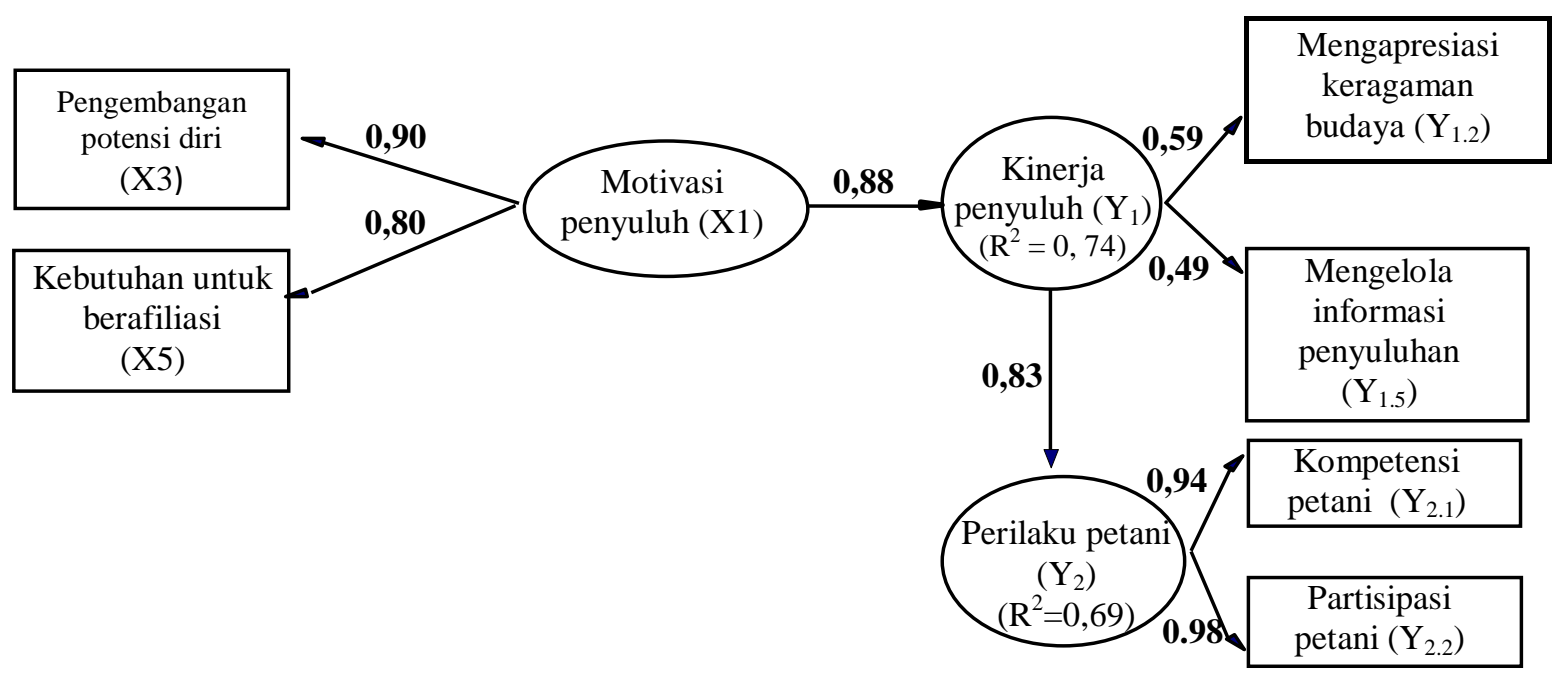

Chi-Square $=71,12, \mathrm{df}=55, \mathrm{P}$-value=0,07076, RMSEA=0,050, CFI=0,97

Gambar1. Model struktural motivasi dan kinerja penyuluh pertanian

Secara keseluruhan hasil analisis menunjukkan hubungan dan pengaruh antar peubah/sub peubah pada model kinerja penyuluh pertanian yang diringkas pada Tabel 1.

Tabel 1. Dekomposisi pengaruh antar peubah model kinerja penyuluh pertanian.

\begin{tabular}{|l|l|l|c|c|c|c|}
\hline \multicolumn{2}{|c|}{ Hubungan antar peubah/sub peubah } & \multicolumn{3}{|c|}{ Pengaruh } & \multirow{2}{*}{$t$-hitung } \\
\cline { 3 - 6 } & Langsung & $\begin{array}{c}\text { Tdk } \\
\text { langsung }\end{array}$ & Total & \\
\hline Motivasi penyuluh & $\longrightarrow$ & Kinerja penyuluh & 0,88 & - & 0,88 & 3,34 \\
\hline Motivasi penyuluh & $\longrightarrow$ & - & 0,52 & 0,52 & 5,17 \\
\hline Motivasi penyuluh & keragaman budaya & $\begin{array}{l}\text { Mengelola informasi } \\
\text { penyuluhan }\end{array}$ & - & 0,44 & 0,44 & 4,45 \\
\hline Motivasi penyuluh & $\longrightarrow$ & Perilaku Petani & - & 0,73 & 0,73 & 4,52 \\
\hline Motivasi penyuluh & $\longrightarrow$ & Kompetensi petani & - & 0,69 & 0,69 & 6,61 \\
\hline Motivasi penyuluh & $\longrightarrow$ & Partisipasi petani & - & 0,72 & 0,72 & 6,89 \\
\hline Kinerja penyuluh & $\longrightarrow$ & Perilaku Petani & 0,83 & - & 0,83 & 2,84 \\
\hline Kinerja penyuluh & $\longrightarrow$ & Kompetensi petani & - & 0,78 & 0,78 & 4,01 \\
\hline Kinerja penyuluh & $\longrightarrow$ & Partisipasi petani & - & 0,82 & 0,82 & 4,07 \\
\hline
\end{tabular}

Keterangan: $\mathrm{t} 0,05$ tabel $=1,96$

\subsection{Pengaruh Motivasi dan Kinerja Penyuluh Pertanian dalam Pengembangan Usahatani Jagung.}

Hasil penelitian menunjukkan bahwa peubah motivasi berpengaruh nyata pada kinerja penyuluh pertanian. Hal ini berarti motivasi penyuluh ikut menentukan baik-buruknya kinerja penyuluh pertanian dalam mengubah perilaku petani jagung. Tabel 1 menunjukkan adanya pengaruh langsung variabel motivasi penyuluh pada kinerja penyuluh pertanian sebesar 0,88 
yang berbeda nyata pada $a=0,05$. Secara matematik persamaan model struktural kinerja penyuluh pertanian adalah: $\mathrm{Y} 1=0,88 \mathrm{X}$.

Hasil penelitian menunjukkan bahwa peubah motivasi penyuluh berpengaruh nyata pada kinerja penyuluh pertanian, berarti peubah motivasi ikut menentukan baik-buruknya kinerja penyuluh pertanian dengan koefisien pengaruh sebesar 0,88 yang nyata pada $a=0,05$. Hal ini mengindikasikan, jika terjadi peningkatan satu satuan motivasi penyuluh pada dimensi pengembangan potensi dan kebutuhan untuk berafiliasi, akan meningkatkan kinerja penyuluh pertanian mengapresiasi keragaman budaya sebesar 0,52 satuan dan sekaligus meningkatkan pengelolaan informasi penyuluh pertanian sebesar 0,44 satuan. Dimensi motivasi penyuluh yang berhubungan erat dengan kinerja penyuluh pertanian adalah: (1) pengembangan potensi diri, meliputi: harapan berkesempatan mengikuti pendidikan formal, pelatihan dan melakukan percobaan lapangan teknologi spesifik lokasi dan (2) kebutuhan untuk berafiliasi, meliputi: keinginan untuk diterima orang lain di lingkungan penyuluh tinggal dan bekerja, keinginan untuk dihormati, keinginan untuk maju dan tidak gagal dan keinginan untuk ikut serta (berpartisipasi).

Hasil penelitian ini sejalan dengan hasil penelitian Haryadi, dkk (2001) yang menyimpulkan bahwa peubah motivasi berpengaruh pada kinerja penyuluh pertaniandi Kabupaten Musi Banyuasin dengan koefisien determinasi (R2) sebesar 66,8 persen yang nyata pada $a=0,05$. Secara teoritis penelitian ini searah dengan pendapat Gilley dan Enggland (1989) yang menyatakan bahwa, motivasi merupakan kemampuan yang dimiliki seseorang, sehingga yang bersangkutan dapat menyelesaikan tugasnya.

\subsection{Pengaruh Motivasi dan Kinerja Penyuluh Pertanian pada Perilaku Petani Jagung.}

Motivasi dan kinerja penyuluh pertanian secara langsung berpengaruh nyata pada perilaku petani jagung, hal ini dapat dilihat dari pengembangan potensi diri, kebutuhan berafiliasi, mengapresiasi keragaman budaya, dan mengelola informasi penyuluhan. Tabel 1 menunjukkan pengaruh peubah motivasi dan kinerja penyuluh pertanian pada perilaku petani jagung, yaitu: 0,73 dan 0,83 yang nyata pada $\alpha=0,05$. Peubah motivasi penyuluh berpengaruh tidak langsung pada perilaku petani jagung, sedangkan kinerja penyuluh pertanian berpengaruh langsung pada perilaku petani. Hasil penelitian menunjukkan bahwa peubah motivasi dan kinerja penyuluh pertanian berpengaruh nyata pada perubahan perilaku petani jagung (Gambar 1). Perubahan perilaku petani jagung tersebut nampak pada perubahan kompetensi petani jagung sebesar 0,78 satuan dan sekaligus perubahan partisipasi petani sebesar 0,82 satuan (Tabel 1).Dampak pengaruh kinerja penyuluh pertanian pada perubahan perilaku petani jagung koefisien determinasinya (R2) sebesar 69 persen dan sisanya 31 persen merupakan pengaruh peubah lain di luar penelitian ini. 
Kartasapoetra (1997) menjelaskan bahwa, penyuluh pertanian merupakan agen bagi perubahan perilaku petani, yaitu dengan mendorong masyarakat petani untuk mengubah perilakunya menjadi petani dengan kemampuan yang lebih baik dan mampu mengambil keputusan sendiri, yang selanjutnya akan memperoleh kehidupan yang lebih baik. Melalui peran penyuluh, petani diharapkan menyadari akan kekurangannya atau kebutuhannya, melakukan peningkatan kemampuan diri dan dapat berperan di masyarakat dengan lebih baik. Hal ini dijelaskan melalui penelitian Muliady, (2009) yang menyimpulkan bahwa, faktor-faktor yang berpengaruh pada perilaku petani adalah motivasi petani mencapai keberhasilan, wawasan petani, keaktifan petani mencari informasi dan intensitas penyuluhan.

\subsection{Pengaruh Kinerja Penyuluh Pertanian pada Perubahan Perilaku Petani Jagung.}

Hasil penelitian menunjukkan bahwa variabel kinerja penyuluh pertanian berpengaruh nyata pada perubahan perilaku petanian jagung melalui dimensi mengapresiasi keragaman budaya dan mengelola informasi penyuluhan. Tabel 1 menunjukkan peubah kinerja penyuluh pertanian berpengaruh tidak langsung pada kompetensi dan partisipasi petani jagung, sehingga secara matematik persamaan model struktural perilaku petani jagung adalah: Y2 = 0,83 Y1. Berdasarkan Gambar 1 kinerja penyuluh pertanian berpengaruh pada perubahan perilaku petani jagung dengan koefisien determinasi sebesar $69 \%$. yang berarti kontribusi kinerja penyuluh pertanian pada perubahan perilaku petani jagung melalui kompetensi petani berusahatani dan partisipasi petani mengikuti kegiatan penyuluhan sangat baik. Oleh karena itu peran pemerintah pusat dan daerah dalam meningkatkan kinerja penyuluh pertanian melalui kebijakan perbaikan anggaran dan sarana penyuluhan dengan memperhatikan motivasi dan kinerja penyuluh memiliki arti yang sangat strategis dalam pengembangan produksi jagung, sebab kinerja penyuluh pertanian yang baik akan berdampak pada perubahan perilaku petani jagung ke arah yang lebih baik pula dalam meningkatkan produktivitas usahatani jagung.

\section{Kesimpulan}

Berdasarkan hasil penelitian dan pembahasan, maka kesimpulan penelitian ini dapat dijelaskan sebagai berikut:

(1) Pengaruh motivasi pada kinerja penyuluh pertanian dipengaruhi oleh dimensi kemampuan pengembangan potensi diri dan kebutuhan berafiliasi.

(2) Peubah motivasi penyuluh berpengaruh tidak langsung pada perubahan perilaku petani jagung, sedangkan kinerja penyuluh pertanian melalui dimensi kualitas mengapresiasi keragaman budaya dan kualitas pengelolaan informasi berpengaruh langsung pada perilaku petani dengan koefisien pengaruh sebesar 0.83 satuan. 
Dampak pengaruh kinerja penyuluh pertanian pada perubahan perilaku petani jagung melalui dimensi kompetensi petani dan partisipasi petani dengan keofisien determinasi $\left(\mathrm{R}^{2}\right)$ sebesar 69 persen.

\section{Daftar Pustaka}

Arikunto, S.,. 2010. Prosedur Penelitian Suatu Pendekatan Praktik. Rineka Cipta: Jakarta.

BPS, 2015. Produksi Perkebunan Menurut Provinsi dan Jenis Tanaman. http://www.bps.go.id. Diakses pada tanggal 19 Oktober 2015: Makassar.

Fahmid, I.M., 2013. Social Innovation Among Ethnics in Cocoa Farming at Sulawesi, Indonesia. Journal of Biology, Vol.3, No.11.

Firdaus, 2015. Teknologi Sambung Samping dapat Meningkatkan Produktivitas Kakao Petani di Provinsi Aceh. http://nad.litbang.pertanian.go.id. Diakses pada tanggal 6 April 2015: Makassar.

Husna, N., M.S.S. Ali, D. Salman, P. Hijjang, F. Djufry, A.A. Amrawaty, 2015. Merging Indigeneous Knowledge and Modern Knowledge in Agricultural Development. IJAS, Vol.2, No., 2.

Nai, E., 2013. Rehabilitasi Kakao dengan Metode Sambung Samping. http://nad.litbang.pertanian.go.id. Diakses pada tanggal 6 April 2015: Makassar.

Salman, D., 2016. Sosiologi Desa: Revolusi Senyap dan Tarian Kompleksitas. Makassar: Ininnawa. 